\title{
Thermal simulation of an actuator
}

\author{
Lizeta Popescu ${ }^{1}$, and Lucian Diodiu ${ }^{2, *}$ \\ 1 "Lucian Blaga" University of Sibiu, Engineering Faculty, Computer and Electric Engineering \\ Department, Emil Cioran Street, No. 4, 550025 Sibiu, Romania \\ 2 Energoconsult, Viile Sibiului no.1, Sibiu, Romania
}

\begin{abstract}
The paper presents a method for verifying the thermal stability of an actuator with axial symmetry as a final stage of its assisted design. Thermal simulation of electromagnetically and cinematically optimized actuator is done by the Finite Element Method in Comsol Multiphysics (Heat Transfer Module). The thermal simulation is based on the geometry drawn in the Catia V5 and the material characteristics. Thermal simulation reduces the time and cost of designing actuators and prototypes.
\end{abstract}

\section{Introduction}

The modern methods of assisted design of electrical equipment and machines consist of their analytical design and their optimization by electromagnetic and thermal simulations, in order to reduce the time and cost of prototyping and designing.

Actuators are electromagnets used in most industries, from the construction of switchgear to electromagnetic coupling. The thermally simulated actuator is used in the AFFP (active force feedback pedal) automotive industry [1-4].

Determining the temperature variation both inside the actuator and especially at its surface is because the position of the actuator studied in the vehicle is one that can affect the driver if the temperature reached by the driver is not within certain limits.

After constructive optimization of the actuators by electromagnetic and cinematic simulations, it is necessary to assess the thermal stress to which the sub-assemblies are subjected to determine the thermal stability in various operating modes [2].

Thermal simulation was done in the Comsol Multiphysics 4.3 program, the Heat Transfer Module, which is used by production designers, developers, and scientists to study the influence of heating or cooling on different electrical appliances or processes. The high-level details of this type of simulation give us the opportunity to optimize the design and operational conditions of the heat transfer devices and processes.

The thermal transfer module supports all the fundamental mechanisms of heat transfer, including conductivity, convection and thermal radiation (both surface and surface - the environment). By using the physical interface in this module, temperature can be modeled in parallel with other physical laws, a powerful combination that makes simulated models more representative of reality [2].

\footnotetext{
* Corresponding author: lucian_diodiu@yahoo.com
} 


\section{Generate the 3D model in CATIA V5}

On the basis of the 2D (Fig.1) optimized constructive actuator documentation (by optimizing the magnetic induction in the actuator and obtaining the electromagnetic force values in its moving parts), we completed the 3D model of the actuator in CATIA V5 of IBM PLM (Product Lifecycle Management).

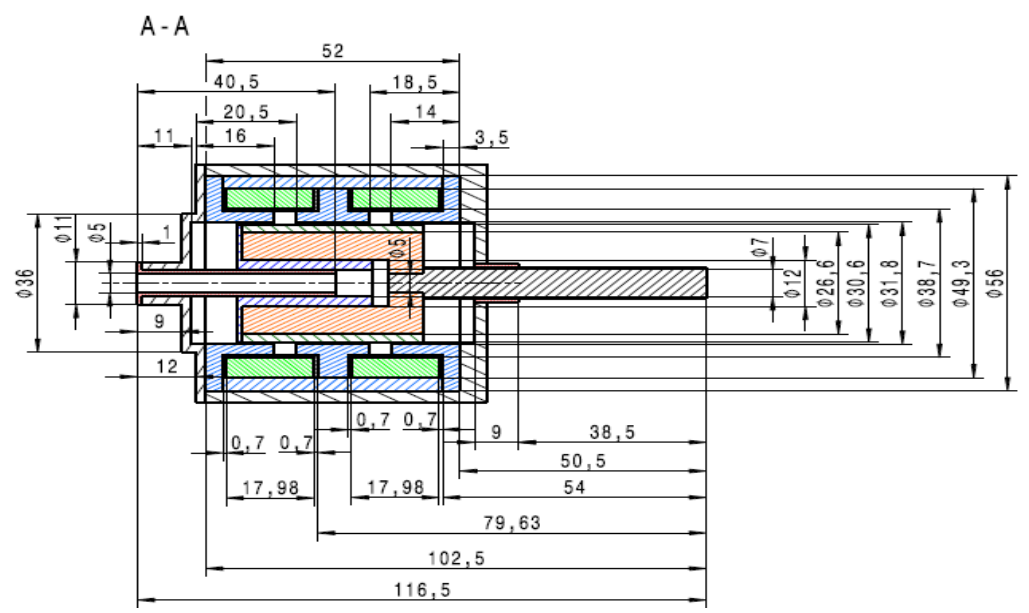

Fig. 1. Axial actuator 2D model.

The choice of the CATIA V5 offers many advantages: besides being very easy to use, it has increased flexibility and scalability, and capturing and reusing data leads to increased productivity, reducing time and cost of design (Fig. 2) [1].

The PART DESIGN module of CATIA V5 meets the requirements and requirements of the simulation method, ensuring a very fast and inexpensive optimal design of electrical equipment and machines, and allows the modeling of a product based on the 2D (xOy) model made using the Sketcher. Part Design delivers with components (features, features) and bodies [4].
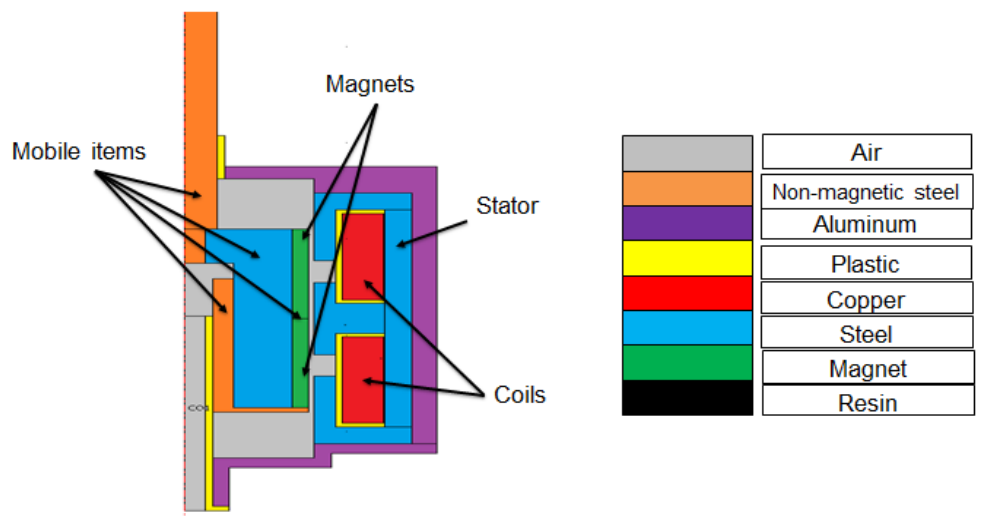

Fig. 2. 3D model with highlighting component materials.

\section{Thermal actuator simulation}

The technical characteristics used in the thermal simulation of the actuator are: Diameter of coil spool: 0.008 [m], Coil width: 0.0052 [m], Coil height: 0.018 [m], Nominal bobbin resistance: 0.91 [V/A], Supply voltage: 12 [V], Copper thermal constant: 0.0039 [1/K], 
Initial thermal equilibrium temperature: 293.15 [K], Spike area: 5.02e-7 [m²], Magnetic Remanufacture: 0.67 [T], Thermal conductivity of the magnet: $7.7[\mathrm{VA} / \mathrm{m} / \mathrm{K}]$, Specific heat of the magnet: $502[\mathrm{~J} / \mathrm{kg} / \mathrm{K}]$, Magnet Density: $7700\left[\mathrm{~kg} / \mathrm{m}^{3}\right]$, Iron Thermal Conductivity: 64 [VA/m/K], Iron Specific Heat: 500 [J/kg/K], Iron Density: 7860 [kg / $\left.\mathrm{m}^{3}\right]$, Thermal conductivity of plastic: $0,25[\mathrm{VA} / \mathrm{m} / \mathrm{K}]$, Specific heat of plastic: 1530 [J/kg/K], Plastic Density: $1500\left[\mathrm{~kg} / \mathrm{m}^{3}\right]$, Copper thermal conductivity: $1.5[\mathrm{VA} / \mathrm{m} / \mathrm{K}]$, Specific copper heat: $606[\mathrm{~J} / \mathrm{kg} / \mathrm{K}]$, Copper Density: $7617\left[\mathrm{~kg} / \mathrm{m}^{3}\right]$, Aluminum thermal conductivity: $120[\mathrm{VA} / \mathrm{m} / \mathrm{K}]$, Specific Heat of Aluminum: $963[\mathrm{~J} / \mathrm{kg} / \mathrm{K}]$, Aluminum Density: $2650\left[\mathrm{~kg} / \mathrm{m}^{3}\right]$, Thermal Air Conductivity: $0.025[\mathrm{VA} / \mathrm{m} / \mathrm{K}]$, Specific Air Heat: $1000[\mathrm{~J} / \mathrm{kg} / \mathrm{K}]$, Air density: $1.2\left[\mathrm{~kg} / \mathrm{m}^{3}\right]$, Thermal Resistance Conductivity: 0.22 $[\mathrm{VA} / \mathrm{m} / \mathrm{K}]$, Specific heat of resin: $1600[\mathrm{~J} / \mathrm{kg} / \mathrm{K}]$, Resistance Density: $1700\left[\mathrm{~kg} / \mathrm{m}^{3}\right]$, Thermal conductivity of non-magnetic steel: $16,3[\mathrm{VA} / \mathrm{m} / \mathrm{K}]$, Specific heat of nonmagnetic steel: $440[\mathrm{~J} / \mathrm{kg} / \mathrm{K}]$, Density of non-magnetic steel: $7900\left[\mathrm{~kg} / \mathrm{m}^{3}\right]$.

Working algorithm in electrothermal simulation: [4]

- Comsol Multiphysics 4.3 opens,

- select the dimensional working space (2D, 3D, 2D axially symmetrical, 1D axially symmetrical, 1D),

- I have chosen the way of working: heat transfer in solid,

- set the type of study: in our case, the transient,

- set the type of study: in our case, the transient,

- set operating parameters (electrical current value, electrical resistivity, supply voltage, initial temperature, current density, etc.),

- set global expressions,

- designing 2D or 3D drawing or importing in $\mathrm{CAD}$ format.
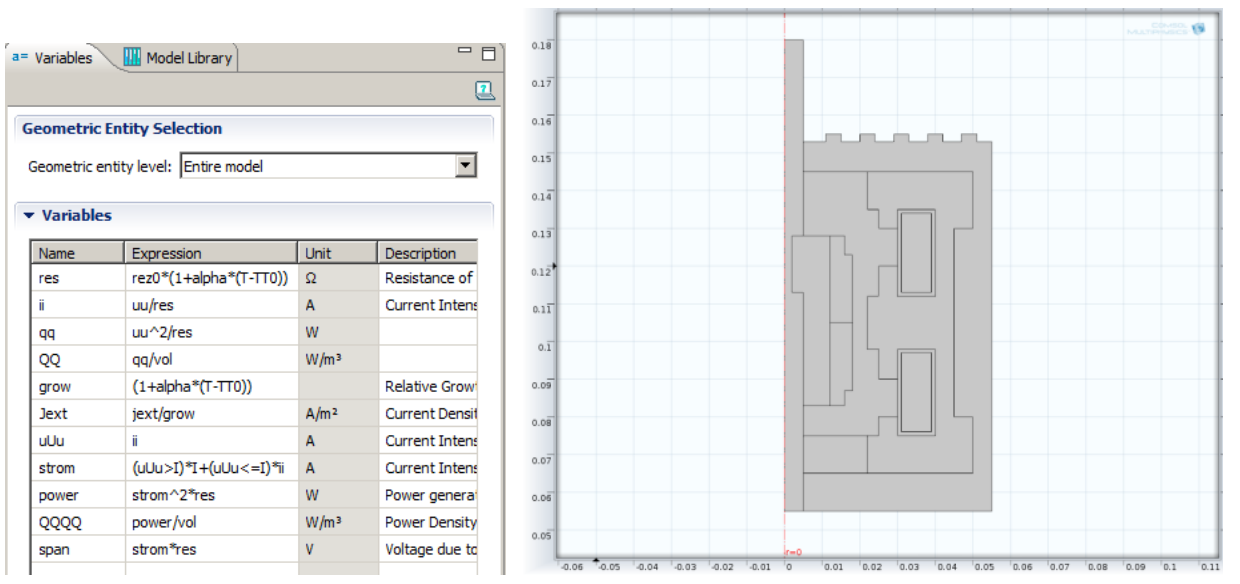

Fig. 3. Making the geometry of the actuator to be simulated.

- set the measuring scale of the piece to be simulated ( $\mathrm{mm}, \mathrm{m}, \mathrm{dm}$, etc.),

- converts the object into solid,

- The object is divided into subdomains,

- Set the materials by domains and material properties.

- Setting the materials by domains.

- Set the initial temperature on all subdomains,

- Set boundary conditions.

- set a heat flow and its characteristics:

-will set the heat transfer coefficient

-will set the outdoor temperature

-the type of radiation will be set 
-it will set the surface emissivity

-The ambient temperature will be set.

- Further, the meshing will be performed, which will be done either entirely on the whole field, or selectively on different sub-domains where a finer meshing is desired (Fig.4).

- Refine the meshing of the elements.

- Further, the parameters of the simulation are worked out, more precisely the type of the analysis (transient, stationary), in our case being a transient simulation, it is set the time on which the simulation is to be made.

- The simulation resolve button is activated.

- The results are read and interpreted [4].

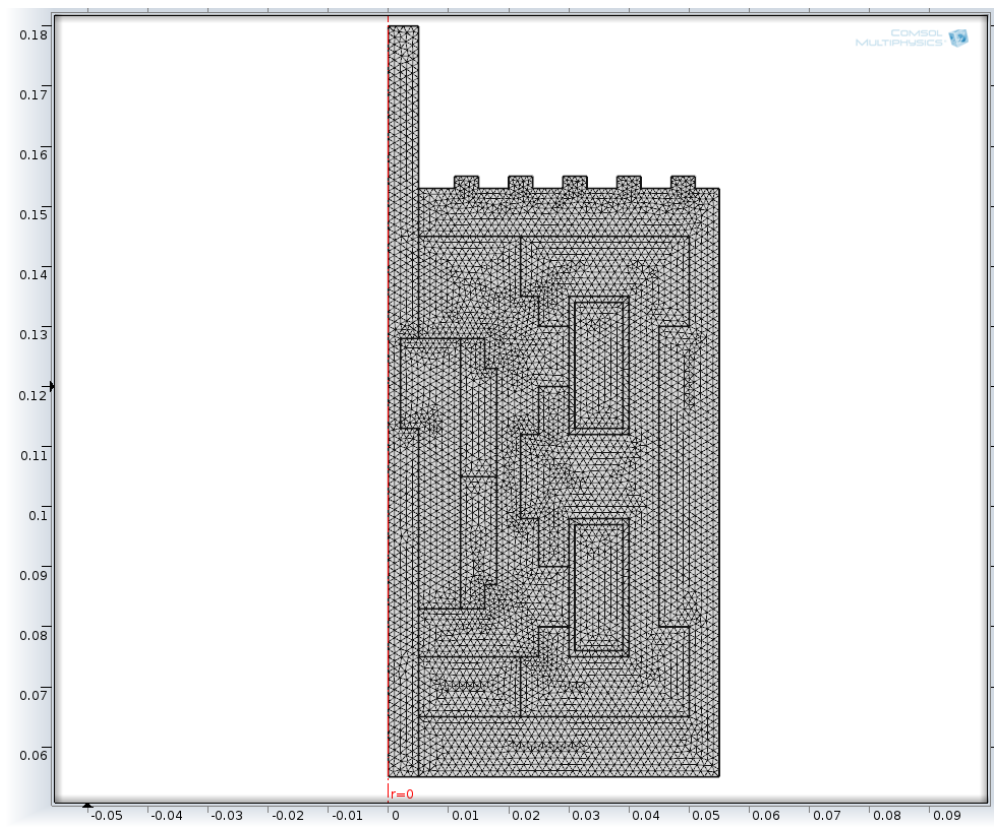

Fig. 4. Model Discretization [4].

\section{Thermal actuator results}

We performed the thermal simulation of the three-purge actuator: 4, 8 and $12 \mathrm{~A}$. We did the analysis for a $3000 \mathrm{~s}$ transient, which corresponds to the actuator's practical operation [3].

The results of the simulation are presented in Figures 5, 6, 7 and in Figure 8 we presented the time variation of the temperature at the actuator surface for the current of $12 \mathrm{~A}$.

To understand the possibilities of improving the cooling regime in Fig. 9, it showed the variation of the heat flow in and through the actuator at the 12 A current.

Since checking the accuracy of the thermal simulation is not possible by measuring the temperature inside the actuator (due to its small size and compact construction), we have opted for temperature measurements at the surface of the actuator with a I7-FLIR thermal imaging chamber.

A good concordance between simulation and experimental results (errors of up to 4 $\mathrm{K})$ has been achieved, but this is influenced by adjacent environments and cooling conditions. 

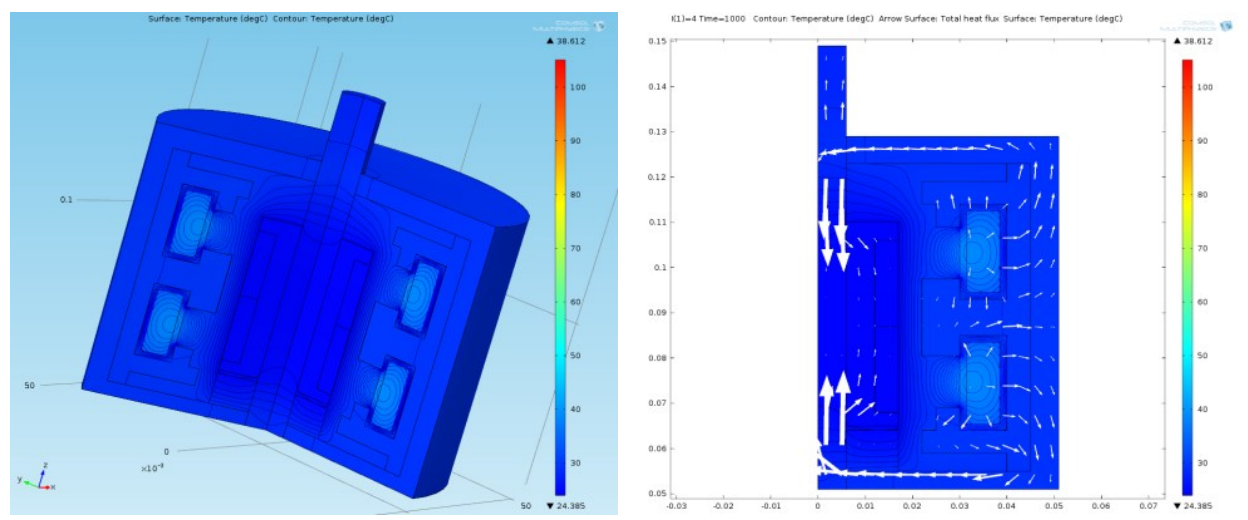

Fig. 5. Thermal actuator results for $4 \mathrm{~A}$.
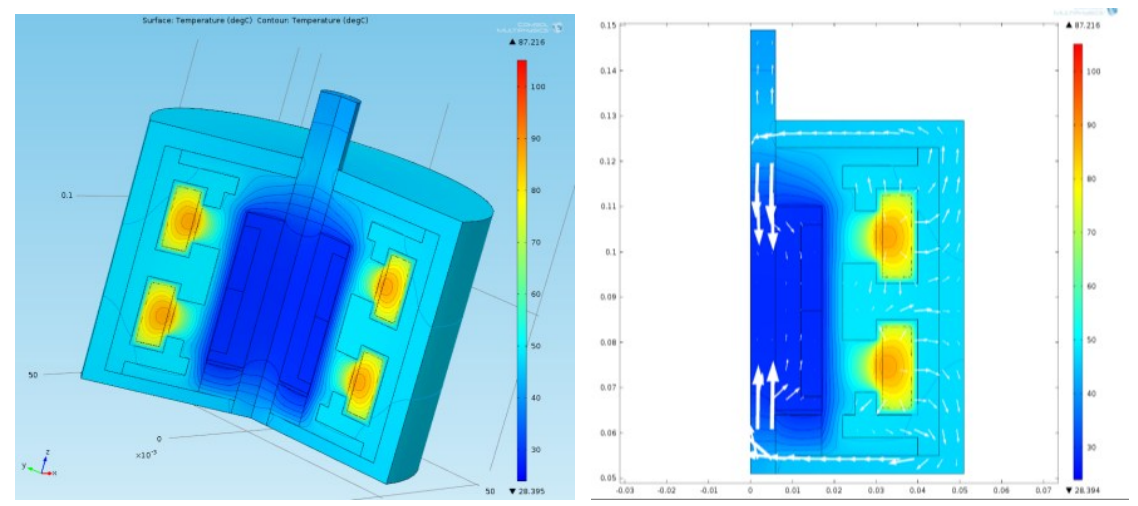

Fig. 6. Thermal actuator results for $8 \mathrm{~A}$.
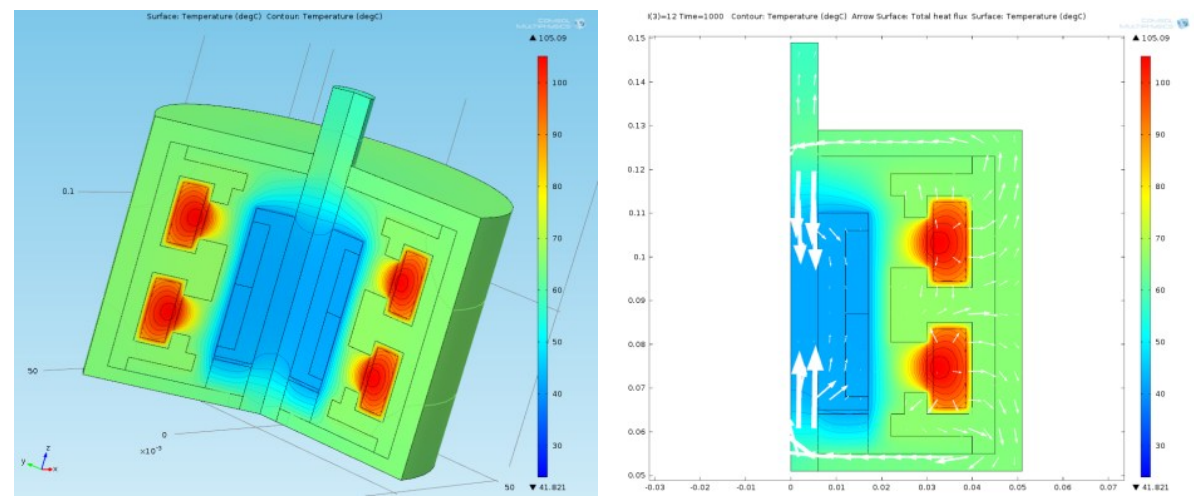

Fig. 7. Thermal actuator results for $12 \mathrm{~A}$.

Much more important is the temperature variation over time (Fig.8) and the evaluation of the thermal flows in the actuator (Fig. 9) that allow the choice of the housing type and the thermal interaction with the adjacent subassemblies.

\section{Conclusions}

The thermal simulation method of an actuator, presented in the paper, is based on the finite element method, and allows for a rapid assessment of the thermal stability of the 
reactor, but also of the influence of the thermal fluxes it has on neighboring devices or on the human operator.
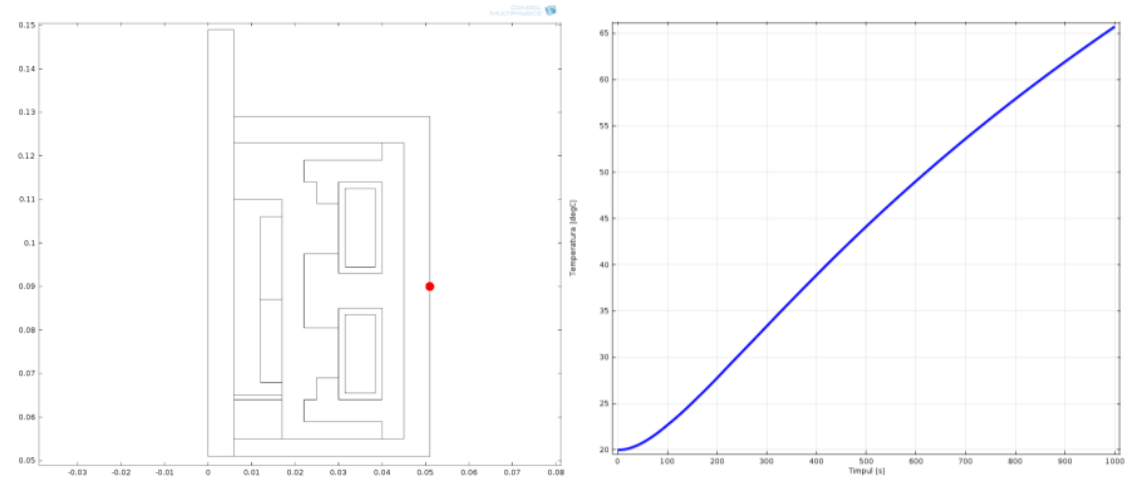

Fig. 8. Time variation of temperature at actuator surface for 12 A current.
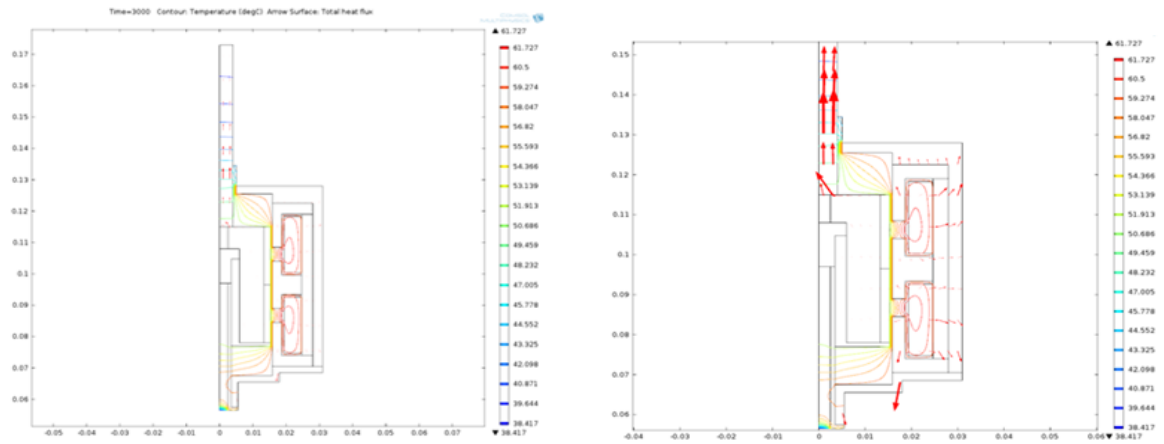

Fig. 9. Heat flow variation in and through the actuator at $12 \mathrm{~A}$.

Based on the simulation of the thermal processes in a transient mode, as much as the real operating mode, resources can be determined to improve the cooling conditions, the judicious choice of the sensitive thermal materials or the miniaturization of the actuator.

Together with electromagnetic simulation (designed to optimize the magnetic circuit of the actuator) and the determination of kinematic characteristics (displacement force), thermal simulation is strictly necessary for the optimal design of the actuator.

\section{References}

1. E.G. Thompson, Introduction to the Finite Element Method: Theory, Programming and Applications, J. New York, Wiley \& Sons Publishers (2004)

2. L. Popescu, D. Bînă, Calculating the thermal field of a magnetic separator, International PCIM Conference Power Electronics, Intelligent Motion, Power Quality, Nürnberg, Germany (2006)

3. L. Popescu, Echipamente electrice, Ed. Alma Mater, Sibiu (2008)

4. G. Dhatt, E. Lefrancois, G. Touzot, Finite element method, John Wiley \& Sons (2012) 